\title{
Face-to-Face with Place: Place-Based Education in the Fraser Canyon
}

\author{
Teresa Farrell \\ Instructor, Faculty of Education \\ Vancouver Island University \\ Teresa.Farrell@viu.ca \\ Paula Waatainen \\ Instructor, Faculty of Education \\ Vancouver Island University \\ Paula.Waatainen@viu.ca
}

This work was supported by funding received from a Social Sciences and Humanities Research Council (SSHRC) Exchange Grant, a Vancouver Island University Innovate Grant, and funds from the Faculty of Education, Vancouver Island University.

Two instructors from the Faculty of Education at Vancouver Island University organized a three-day field experience with 35 pre-service teachers along the Fraser Canyon corridor, home of the Nlaka'pamux and Stó:lō Nations. We asked: How will an educational field experience in this place impact and inform pre-service teachers and researchers' understanding of placebased education (PBE) in their practice? We explore the shift towards Indigenous perspectives that subtly wove its way through the work and how it framed new ways of thinking about place for our participants and new ways of considering decolonizing education for the instructor researchers. We conclude by arguing that PBE is necessitated by active, living relationship in place and provides opportunities for critical pedagogy grounded in Indigeneity. We also suggest that both Indigenous and non-Indigenous educators have a role to play in this work.

"Is it not time to face place - to confront it, take off its veil and see its full face." (Johnson and Murton, 2007, p. 127).

On September 12, 2019, two instructor researchers traveled with 35 pre-service teachers to a place that lived in our minds and hearts: the Fraser Canyon corridor ${ }^{1}$, in what is now British Columbia, Canada. We were seeking to better understand place-based education (PBE), an approach to learning that has gained prominence in the last decade (Lowenstein et al., 2018;

\footnotetext{
${ }^{1}$ The Authors recognize that the name Fraser Canyon is a post contact colonized name. In connecting to Knowledge Keepers in the area, we were hoping to replace this with a term that was more in keeping with this territory and the spirit of this article. We were, however, unable to successfully find an Indigenous place name that referenced the entire canyon or the Fraser River as it crosses through a variety of territories and languages. We mean no disrespect in using this colonized term.
} 
Madden, 2019; McInerney et al., 2011). We wondered about the nature of PBE and its potential in our practice as teacher-educators and for our pre-service teachers. The 2019 trip was the second design iteration of a field experience trip that we had planned in 2018. We both knew the Canyon as a remarkable place where geography and human history intersect in powerful ways. We hoped that by modelling place-based learning in the Fraser Canyon we would help students apply historical and geographic thinking concepts authentically and build their understanding of PBE. The 2019 iteration of the trip was built on the successes of the first trip but included a significant reframing of our itinerary and a research study. In 2018 we were practitioners of PBE with limited theoretical underpinning, so the purpose of our study was to build what Bereiter (2014) calls principled practical knowledge (PPK) of PBE in order to support building it in our students. PPK addresses gaps between theory and practice by adding some "know why" to building "know how" to support practitioners in addressing practical problems (Bereiter, 2014, p. 5 ). While our research purpose had a focus on our own practice and on our students, the data we collected indicated an unexpected aspect of our trip connected to decolonizing education. This is what we chose to focus on further in writing this article.

We begin by highlighting the theoretical insights that inspired our work. We then discuss the intentional design that influenced the itinerary of our PBE project in the Fraser Canyon. After briefly describing the methods used in this study, we identify and discuss themes that arose from the data specific to PBE and decolonizing education. We end with a conclusion offering questions and areas for further study.

\section{Theoretical Context}

There has been a growing movement globally in the last decade to include Indigenous perspectives, knowledge and pedagogical approaches in education through policy, program, and curricular reform (Aitken \& Radford, 2018; Madden, 2019). In 2007, the United Nations declared The Rights of Indigenous Peoples and officially formalized a space for and a right to Indigenous Knowledge Systems (Battiste \& Henderson, 2009). This right was further legitimized in Canada with the Truth and Reconciliation Commission Report in 2015 where educators were specifically tasked with becoming part of the reconciliation process by helping students learn about colonization and its ongoing impacts on Indigenous people and communities (Aitken \& Radford, 2018). In British Columbia, Standard 9 of the Professional Standards requires educators to foster "a deeper understanding of ways of knowing and being, histories, and cultures of First Nations, Inuit and Métis" (BC Teachers Council, 2019, p. 3). Such curricular mandates reflect a common felt "urgency of creating conditions for future teachers to learn to teach for reconciliation" (Aitken \& Radford, 2018, p. 47).

Recent research suggests that PBE is a methodology that could answer this call (Gruenewald, 2003; Johnson, 2012; Madden, 2019; Simpson, 2004). In this regard, Indigenous 
scholars and educators such as Cajete, Battiste and Henderson have been articulating ties between Indigenous knowledge systems and PBE (Aitken \& Radford, 2018; Battiste \& Henderson, 2009; Simpson, 2004). Indigenous Knowledge is now being recognized and held up after being marginalized for so long. Battiste and Henderson (2009) referred to this dynamic as the "recognition and activation of Indigenous Knowledge" (p. 5). To foster this recognition, Johnson and Murton (2007) highlighted the importance of “modern Indigenous authors' ability to relate the foundational stories of their communities' knowledge systems to modern audiences, providing new voices to the healing of this disjunction between nature and culture in place" ( $\mathrm{p}$. 125).

Simultaneously, through the works of critical theorists such as Friere and Giroux, critical theory is making its way into the conversation surrounding PBE (Gruenewald, 2008; Seawright, 2014). Seawright (2014) suggested that PBE provides a platform for hearing Indigenous epistemic resistance to dominant settler understandings of place. However, as Gruenewald (2008) stated, "critical place-based pedagogy cannot be only about struggles with human oppression. It also must embrace the experience of being human in connection with the others and with the world of nature" (p. 314). Offering the possibility for a new lens for the pedagogy of place, Battiste (2013) also described critical theory as a method to recognize fragmented and diminished perspectives and to bring them forward for decolonizing education.

This is certainly a worthy goal, but how is it achieved? Battiste (2013) called on educators "to respectfully blend Indigenous epistemology and pedagogy with Euro-Canadian epistemology and pedagogy to develop an innovative ethical, trans-systematic Canadian educational system" (p. 168). Madden (2019), building on the work of Battiste, further described decolonization as a process of deconstructing and reconstructing. Deconstructing reveals and challenges the long-held assumptions of pervasive colonial systems that generate inequities and misrepresentations, while, as Madden (2019) asserted, "reconstructing advances educational change rooted in Indigenous epistemologies, ontologies, and community priorities that are deeply relational and place-based" (p. 287). Madden (2019) further noted that "decolonization need not be (and perhaps cannot be) constructed in neat opposition to colonization" (p. 287). This conceptualization of decolonizing practices pushes past a simplified and potentially polarizing binary opening up a space for a more complex understanding.

For over a decade, Professor Martin Nakata, a Torres Strait Islander, has led the academic discussion on Indigenous Studies in Australia and offers a possible process for this complex understanding. He posed a theory called cultural interface, a complex space where both Indigenous and Western knowledge coexist in all their contradictions to inform each other and provide opportunities for intercultural learning (Carey \& Prince, 2014). In this article we consider whether the idea of a cultural interface offers a method of inclusion and recognition of multiple perspectives with deep integration. This would not be to support and perpetuate a 
colonized view, but to recognize and examine colonial narratives alongside Indigenous perspectives. As Marom and Rattray (2019) asserted, "the cultural interface calls for an interrogation and mapping of Indigenous-settler relations from the standpoint of complexity and reciprocity" (p. 2). In designing and enacting our field work with pre-service teachers, we were not trying to replace or deny a colonized narrative of the Fraser Canyon Gold Rush but to add perspectives, details, stories, and experiences to better understand the complex and intertwined histories of this place.

\section{The Shape of Our Work}

\section{Building Relationships}

Our PBE research project was our second trip to the Fraser Canyon with students. Our first trip informed our design of the itinerary used in our research project. In designing both field experiences for our students, we chose to reach into community for expertise and guides as well as striving to provide multiple lenses and perspectives to experience this place: the Fraser Canyon corridor. This idea of providing various perspectives was multi-disciplined and geographical. We intentionally experienced this place from roads, trails, mountain heights and the river, and we assembled a team of guides representing different perspectives on the Canyon. For our 2018 trip, we invited Dr. Daniel Marshall, an award-winning historian of the Fraser Canyon War, to travel with us and help design our itinerary. We also connected with Charles Hou, a retired social studies teacher who for decades brought his high school classes to hike historic trail systems in the region. Byron Spinks, Knowledge Keeper and manager of Tuckkwiowhum Heritage Interpretive Village developed a component of our field work as well as geographer Michael Kennedy. We also arranged a trip on the river with Fraser River Raft Expeditions, whose expertise in guiding raft trips were part of both the 2018 and 2019 PBE trips.

During the year between the trips, we stayed connected to this group, sharing memories and ideas for our next trip. Obviously, the first trip could inform our second trip but the building of relationships that occurred was also a critical factor. Familiarity, trust and understanding were built among the facilitator and guides. We were, for example, hoping to secure a welcome to the territory to begin our second trip (Battiste \& Henderson, 2009; Greenwood, 2019). It was only with the diligent assistance of Knowledge Keeper Byron Spinks that this happened as he connected us to Knowledge Keeper Ernie Michell. Another wonderful addition to our project was archaeologist and instructor Brian Pegg from Kwantlen Polytechnic University who runs the Applied Anthropology Field School in conjunction with the community in the area. We were also joined by Dr. Lindsay Gibson, an assistant professor in the Department of Curriculum and Pedagogy from UBC, who knew about our first trip and had volunteered to come along on our second. He is an admirer of Charles Hou's immense contributions to the teaching of Canadian 
history. These eclectic connections formed a web of relationships that provided a firm foundation for our work.

\section{The Design of the Itinerary}

Dorst (2011) suggested that designers work with a basic equation of what + how $=$ value. As experienced designers of learning activities and field trips, we were operating with an equation of Fraser Canyon field trip + PBE approaches = ability of pre-service teachers to apply historical and geographic thinking competencies and build principled practical knowledge of PBE. While the 2018 field trip seemed successful, something about our itinerary felt incomplete. We had started on a beach in Yale, BC, as our students were asked to imagine the boom town that appeared at that site when thousands of miners flooded into the area looking for gold in 1858.

\section{Indigenous Inclusion}

In the second iteration of our trip we sought to make Indigenous Inclusion a theme that wove its way throughout the design, the experience, and consequently the data. Noting the ways PBE is often seen as a location for Indigenous inclusion (Cajete, 2014; Gruenewald, 2003; Johnson, 2012; Simpson, 2004), we explicitly wanted to move respectfully through the territory. As Greenwood (2019) advocated, "land acknowledgement is an essential part of how I view place acknowledging Indigenous inhabitance of land and the legacies of colonialism” (p. 368).

Seeking to shift our design in ways that might set a tone for this kind of work, we intentionally reframed the design of our 2019 trip to begin in a different location, and thousands of years earlier with Knowledge Keeper Ernie Michell welcoming us to the Nlaka'pamux territory. This choice was informed by Battiste and Henderson (2009) who advocated "learning by following appropriate and consensual protocols allow[ing] teachers to enter into, comprehend, respect and animate Indigenous Knowledge" (p. 17). The group gathered at the meeting of the rivers, T'kemtsin (Lytton, BC), where Knowledge Keeper Ernie Michell, from the Siska/Kanaka band, welcomed us to the territory and shared stories of this place and its people. He then sang a song and said a prayer to protect us in our travels on that land.

\section{Re-imagining Core Relationships}

Our next activity was inspired by a science education study by Bang and colleagues (2012) who suggested "the importance of de-settling and reimagining core relations between nature and culture" (p. 314). These scholars explored the boundary of western science traditions and Indigenous knowledge systems by having students collect water samples from an oxbow in a river in a new way. To encourage the students to feel the river and develop a respect and 
relationship for it, they had their students put on waist-high waders and "immerse themselves in the river, erasing the chasm between themselves and the river" (Bang et al., 2012, p. 313). Inspired by this activity, we invited our student-participants to remove their shoes to feel the water and current, and to greet the Fraser River with their feet. This simple activity set a tone to begin our work with this place. The group then took the Lytton reaction ferry to Rip Van Winkle Flats in the Stein Valley where geographer Michael Kennedy revealed the impact of the placer mining in the 1850s Fraser Canyon Gold Rush (Kennedy, 2009).

The next day, we arrived at the Big House at Tuckkwiowhum Heritage Interpretive Village, were welcomed by Knowledge Keeper and manager Byron Spinks and were pleasantly surprised to be reunited with Knowledge Keeper Ernie Mitchell. They sang, did a clearing and talked of their people, the land, and the critical relationship between the two, and further illustrated this with personal stories. This was quite different and more intimate than our more generic 2018 experience. We were grateful for this experience, but this shift was not in our design. We had simply built relationship and provided room for this experience to emerge. Marom \& Rattray, 2019, recommend that "developing relations with local Indigenous leaders and cultural teachers is necessary in order not to learn about, but with Indigenous knowledge keepers" (p. 14).

We then proceeded into a replica pit house where Brian Pegg shared the archeological work he had done nearby in partnership with the Nlaka'pamux community. After lunch, Charles Hou led a hike up the ancient Tikwalus Trail and shared the history of its use by Indigenous peoples, the Hudson's Bay Company fur brigades, and gold seekers. The Yale Historic Site was explored through the lens of Historical Thinking activities, based on the model created and developed by Seixas and Morton (2013), which are used as the basis for the curricular competencies in the revised BC Social Studies curriculum. Throughout the afternoon, groups went to Alexandra Bridge Provincial Park to walk the spectacular bridge to nowhere, bearing silent testament to the old Trans-Canada Highway. Dr. Dan Marshall then took us through a tour of Yale itself and painted a picture of Yale in the 1850s, highlighting the historical thinking concept of continuity and change. The facilitators and students then all met for a salmon feast at Fraser River Rafting Expeditions in Yale. On the final day we boarded powered rafts with guides from the Fraser River Raft Expeditions to explore the Fraser River. A fusion of geographic perspective and the complexity of cause and consequence were highlighted at lunch on Chapman's Bar. Dr. Dan Marshall shared the climactic story of the Fraser Canyon War in 1858 when an influx of tens of thousands of gold miners brought tensions and violence between American miner militias and the Nlaka'pamux people to the Canyon in the months before the formal establishment of the colony of British Columbia. Dr. Lindsay Gibson infused connections to curriculum and practice throughout the day's activities. Finally, late on September 14, everyone drove back to catch the ferry home to Vancouver Island. 


\section{Study Methods}

Our study of this experience was guided by the following overarching research question: How will an educational field experience in the Fraser Canyon impact and inform in-service teachers and researchers' understanding of place-based education in their practice?

\section{Research Participants}

Our research participants were students beginning their final semester of a 16-month post-baccalaureate Bachelor of Education program. All students held university degrees in various disciplines, and some had graduate degrees and significant work experience prior to joining our program. Students ranged in age from about 23 to 50, with an approximate average age of 30. All 102 students in our program were invited to participate. Overall, 35 students selfselected to come on our trip in place of doing other place-based work with our colleagues. All students had previously completed their methods courses and a 5-week practicum.

\section{Data Collection and Analysis}

During the three days in the field, pictures and video were taken to document the experience. Researchers also took field notes. Student participants edited a video to share and document their experience with the intention of revealing the nature and impact of PBE on their practice. ${ }^{2}$ To generate more data and gain deeper understanding into the impact of field trip, two weeks later, three lunch time focus groups were undertaken with a total of 31 students organized into three groups (referred to as FG - 1, 2 or 3). The focus group transcripts were then coded using an inductive thematic latent approach (Creswell, 2013) to pull out emergent themes. The video, pictures and researcher field journal notes (FJN) were then used to triangulate and further inform the focus group themes. One theme that emerged from our analysis was connections to Indigeneity, which we labelled Indigenous inclusion. For this article, we chose to examine this theme in particular and connect it to current literature to gain a deeper understanding around possible connections between PBE and Indigeneity.

\section{Themes}

\section{Place as Sites of Resilience}

Indigenous culture is sometimes taught pre-contact as a thing of the past. Although First Nations' cultures in the place now called Canada were severely and negatively impacted by colonization, studying it only from a pre-contact orientation almost implies that the culture and

\footnotetext{
${ }^{2}$ Fraser Canyon Final: https://www.youtube.com/watch?v=tar0UoA3AEg\&feature=youtu.be
} 
the people are extinct, rather than living. A participant described how "going down the river, seeing fishing spots that have been used by families for generations. Seeing their nets, knowing that they have been doing that for so long. It was beautiful to see" (FG-1). Being in this place helped the participant appreciate the resilience of the local Indigenous people. As we rushed the rapids of the Fraser River, we came face to face with the power of this river. A participant remarked how impressed they were by the "ability of the fishers who worked here" and another was in disbelief that anyone could navigate this river at all (FG-3). This appreciation for the various Nations that have always had their home along what is now called the Fraser River would not have arisen without these experiences, coupled with the knowledge gained offering a new lens for seeing this place.

A participant recollected thinking as we rafted the river that the Indigenous fishers were "establishing the ancient traditions of the location that has been a part of this Indigenous community for millennia so it was a real life example of the vibrancy and longevity of the Indigenous people there" (FG-2). Another participant remembered that the rafting guide explained how "all the clothesline equipment always sells out at the hardware store because the clotheslines are used for dip net lines" (FG-2). This participant was struck by the "way that tradition and modern technology have blended" (FG-2). The Indigenous fishers were both past and present: both traditional and contemporary. In this place, past and present are infused and the Indigenous relationship with the land is alive, resilient, and vibrant.

\section{Place Deepens Context, Meaning and Relationships}

In the focus group, participants talked of how walking the land gave context and understanding to their learning and this was the most impactful aspect of PBE for them. This began on our first day when participants were instructed to introduce themselves to the Fraser River. A participant remarked that "touching yourself to water and introducing yourself to nature (FG-1)" influenced their understanding of the Fraser Canyon. Gruenewald (2003) discussed how being in place constructs meaning and that this meaning is co-created between the individual and the place. A participant recalled being engaged in hiking part of the Tikwalus Trail, an Nlaka'pamux trading route that bypasses steep canyon walls. They described this experience as follows:

When we got to the top, there was a sheer cliff below us and it was just hanging there, and the logic of looking from below that wasn't the route that I would consider taking and the explorers probably wouldn't have gone that way without the Indigenous people who already developed these trails. (FG-2)

Basso (1996) wrote that there are moments when people have an acute awareness of place which results in a spontaneous act of reflection that resonates with them. In this reflected moment, this 
participant demonstrated a possible epiphany inspired by being in place. We learned about how the Nlaka'pamux carried hundreds of pounds of goods for hundreds of miles to the interior of BC to trade. Another participant identified this experience as significant learning: "thinking about how hard it was for us. Thinking about First Nations people, carrying the fur with something around their forehead. How strong they were" (FG-1). The colonized and prejudiced view of the heroic explorers and primitive Indigenous people could be disrupted. The explorers and then later the traders that came to this place would not have been able to navigate the land without the help of the Nlaka'pamux who guided them. When referencing this hike in the focus group, another participant stated: "I don't think that I could ever have gotten this concept just from a book learning from other people instead of having my own feet on the trail to walk that place" (FG-2). In designing our place-based field work, we were striving to open spaces for natural connections and stories from the Fraser Canyon corridor. We wanted to facilitate a critical lens coupled with the experience of this place that could open new understandings and viewpoints. As Johnson (2012) stated, "critical pedagogies are inherently pedagogies of place" (p. 834) that can allow for transformations in understanding.

\section{Place as Decolonizer}

An interesting aspect of the data was that many of the participants in the focus group referred to moments of Indigenous inclusion when they were not being guided by an Indigenous person. For example, a participant said: "what struck me was that the local First Nations were the ones to 'discover' the gold" (FG-1). Of course, the people who came from this place and had lived there for a millennium were aware of the gold first. It is our colonized version of history that pictures the newly arrived white man with a gold pan being recognized as the discover. Another powerful shift in thinking that several students noted occurred at Chapman's Bar:

We were by the river standing on the beach and Dr. Dan Marshall was asking what it might have been like for people living there? These newcomers saw this as exploration but what was it like for the people who lived there? I then realised an invasion - yeah that would have been an invasion. So why wasn't it called an invasion in the books? (FG-3)

This insight caused us to ask: "How do you tell the story of this land and who tells it?" (FJN). The Truth and Reconciliation Commission of Canada Calls to Actions (2015) mandates educators to develop and provide curriculum that includes "Aboriginal peoples' historical and contemporary contributions to Canada" (p. 62). This is intimidating for many educators who are non-Indigenous. It was encouraging to note that aspects of Indigenous inclusion might be served by an informed settler educator in the context of place. This insight led us to consider whether learning in place could provide a natural decolonizing force? 
Drawing on Battiste (2013) and Madden (2015), part of decolonizing education is deconstructing colonized incomplete histories and Eurocentric beliefs that perpetuate white settler superiority, and then reconstructing a more holistic understanding inclusive of Indigenous histories, epistemologies, and ontologies. Aitken and Radford (2018) recommended that the first step to decolonizing curriculum is to recognize aspects of our shared history that have been unacknowledged. In the above examples, we were deconstructing decolonization by adding information and perspective through experience in place for a more complete history. A participant said on the ride home "do we really know the history of where we live? Like really know it? It made me think of things differently" (FG-3).

Nakata's idea of cultural interface describes a space for reconciliation where reality is seen as complex, layered, and intertwined rather than oppositional (Martin et al., 2017; Marom \& Rattray, 2019). Madden (2019) similarly advocated for educators to nurture complexities for rigorous examination past the limiting polarized binaries which categorize, simplify, and separate us. Elements of this view were present in our participants' reflections on their experiences. A participant recalled, for example, hiking "where people, both the local First Nations and HBC traders, hiked during trade and during war. That place just brings that to life" (FG-2). Another participant spoke of this complexity: "realizing the Fraser Canyon history is a real mixture of First Nations and Hudson's Bay and how there was so much collaboration between them instead of the narrative that we learned about in the 90's" (FG-2). As Madden (2019) explains, coming to see the layered and intertwined nature of the world is not to eliminate or soften the injustices of the past, but to provide complex context in which to learn. In this less polarized view, it becomes easier to see a more inclusive role for all educators whereby PBE can "bring teachers in relation with situated Indigenous knowledges, as well as Indigenous-nonIndigenous histories and contemporary realities that emerge from interconnected relationships formed in and through place" (Madden, 2015, p. 11).

\section{Indigenous Knowledge}

Madden (2015) also identified streams of Indigenous education including a pedagogy for decolonization and learning from Indigenous traditional models of teaching. Our PBE experience referred to Indigenous inclusion as putting previously marginalized narratives into the center. As one participant remarked: "I appreciated the efforts to integrate the Indigenous perspective. I could see how [curriculums] are moving in that directions even better" (FG-3). Another participant commented: "Yeah the Indigenous perspective. Like I can't even picture the trip without that" (FG-3).

A shift to a more complex, layered, and intertwined understanding of events and place is only still a partial understanding of Indigenous knowledge (Battiste \& Henderson 2009; Simpson, 2004). We do not presume to give a definition of Indigenous knowledge here but 
simply to recognize and reference its potential for transformative forms of learning. PBE intersects with Indigenous knowledge as Indigenous ways of understanding are deeply connected to and inseparable from place (Basso, 1996; Cajete, 2000; Simpson, 2004). This is also not to say that all Indigenous knowledge is entirely uniform, but Indigenous Nations share a certain unanimity in having a relational living relationship with their territory. Indigenous nations are in this way, "place-based, they are, by the very same token, as diverse as the places from which they emanate" (Michell et al., 2008, p. 31).

Simply engaging in PBE does not ensure Indigenous knowledge inclusion as "Indigenous knowledge reflects deep cultural and spiritual connection rooted in lived experiences, authenticity and connection to the land" (Marom \& Rattray, 2019, p. 4). An Anishinaabe from the M'Chigeeng First Nation, Dr. Jan Hare (2012) also stressed that Indigenous knowledge is "inherently tied to land, where meaning and identity are constructed through landscapes, territory and land formations" (p. 292). We believe that in our work in the Fraser Canyon Corridor we were rubbing into this way of understanding. A participant recalled: "being on the river with a guide and [him] telling us, as we are moving along the rock formations, creation stories - that was cool that was awesome" (FG-3). Our rafting guide had been trained by a Stó:1ô Elder Sonny McHalsie (Naxaxalhts'i), and had permission to share this story cautioning us on greed and overfishing. Having the faces and characters forever memorialized in the rock by Xa:ls (the transformer) staring down at you forever in the Th'exelis rock was remarkable (FNJ).

Did we get a glimpse or moments of Indigenous knowledge? In the focus group, a participant remarked: "for instance we talk about reconciliation a lot but my relationship with reconciliation changed when I heard Ernie speak" (FG-2). Another example came from a participant who remembered:

something that was really special for me was being at the Longhouse listening to the elders speak and hearing how Ernie's life questions were answered by a squirrel that summer. This was from this beautiful place that we're currently on and we're sitting here listening to this account and it was really powerful for me to hear about how the place influenced the person in such a profound way. (FG-2)

The moment described above was much more than simply receiving information about a place. It was learning how to connect with a place, learning about the storyteller and learning about ourselves. As we sat listening to Knowledge Keeper Ernie share his story, we also built community and connection of a shared experience and understanding. Given the nature of this research and the fact that both researchers identify as white settlers, it would be poor practice to assert that Indigenous knowledge was an outcome of our experience. A better description would be that at times we glimpsed something through the fog. 
There is a cautionary note to be added here. In attempting to offer PBE as an inclusive methodology, we must be vigilant in checking against misappropriation. We must walk in humility as learners. No matter how positive the intention, Simpson (2004) warns: "coercing our knowledge to conform to the rules of the colonial power structure serves only to further denigrate and attack the nature of Indigenous Knowledge" (p. 380). Madden (2015) examined 23 studies on Indigenous education for pre-service teachers. In her study, she found that "many programs relied on Indigenous Elders and knowledge holders to facilitate co-learning and investigation that activates living Indigenous knowledge" (p. 7). In organizing our Fraser Canyon field work, this was certainly our intention. In our journey as educators towards truth and reconciliation, PBE does have an important role. As Johnson (2012) suggested: "perhaps place offers a 'common ground' between Western and Indigenous thought'” (p. 833).

\section{Conclusion}

An aspect of our research that prompted this article was how naturally the critical pedagogy of place rose up for our student participants. While PBE "does not directly challenge existing power structures, it inherently pushes the dominant settler narrative into question" (Marom \& Rattray, 2019 , p. 5). By walking the land and rafting the river, the capacity of the Nlaka' pamux and Stó:1o People was naturally revealed. By seeing the fishers along the cliffs and by snuggling up by a fire in the replica pit house, a respect, admiration and understanding grew. In this place, the story of the American gold miners who violently imposed themselves, leaving visible scars on the landscape, also lives. This history also included peacemakers: the previously not widely recognized great orator Chief David Spintlum (Sexpínlhemx) of the Nlaka' pamux Nation who held council with leaders and allies to avert war and Captain Henry Snyder, an American gold miner and newspaper correspondent, who underwent a 10-day campaign forging treaties with Indigenous chiefs (Marshall, 2018). Perhaps this is the complexity of Nakata's (2007) cultural interface.

\section{Flexible Design}

A critical aspect in designing this place-based experience was building relationship and trust and then providing spaces for our team to lead the way. Rather than designing a tightly organized and prescriptive itinerary, we opened up opportunities for exploration and time for reflection. This also included the experiencing and building relationship with this place. As Gruenewald (2003) prioritized "learning to listen to what places are telling us-and to respond ... is the pedagogical challenge of place-conscious education" (p. 645). In the focus group, our participants frequently advocated for space "to explore, be hands on, it is so important, so [I] suggest more moments to explore surroundings" (FG-2). By building relationship to a place, as a focus group participant indicated, you can "let the things that you notice lead to curiosity. [It is a] nice lead to inquiry" (FG-1). Bang and colleagues (2012) described a science lesson that was not "aimed at de-settling normative disciplinary constructs, [however], by approaching the 
curriculum as emergent, open territory for intellectual inquiry" (p. 311), these very constructs were questioned by students. As place-based educators we are co-facilitating with place in relationship, providing an informed lens for the experience. As a participant noticed at Alexandra Bridge Park, "you could tell this was a road because of the rock formations. I would never have noticed that. Being taught how to look for things" (FG-3).

\section{Partnership, Community and Relationship}

To truly engage in PBE and open its potential requires building a relationship with place including the people of the place (Greenwood, 2019). In building our team of facilitators and guides, we wanted a diversity of perspectives: the historian, the geographer, the Knowledge Keepers, the archaeologist, the educators, and the river rafting guides. This was achieved by networking and building relationships with people working in and committed to this place. The team was critical in helping determine the nature of this work and framing the learning. As the team gathered on the last night on the porch of Teague House:

The conversation jump[ed] and cycle[ed] weaving disciplines and interests while building relationship with each other and this place. We are all in love; star struck, engrossed in every nuance of this place. This is what we want to share: how this place teaches us, touches and changes us. (FJN)

Although a diverse interdisciplinary team, we were all connected by our relationship to this place. The importance of beginning and including the Knowledge Keepers cannot be underestimated as they "have the ability to relate the foundational stories of their communities' knowledge systems to modern audiences, providing new voices to the healing of this disjunction between nature and culture in place" (Johnson \& Murton, 2007, p. 125). In doing the deconstructing and reconstructing work of decolonization (Madden, 2015), Indigenous voices are mandatory, or colonization is perpetuated (Simpson, 2004). Gruenewald (2008) is convinced that Indigenous educational processes and epistemologies need to be at the center of place-based, culturally responsive teaching"' (p. 151) — a worthy, but difficult goal.

\section{Moving Forward}

Our intention with this article was not to reach definitive conclusions about PBE, we were seeking to inform our understanding of PBE in our practice by getting our toes wet in what is now called the Fraser River. Our study did not look at readiness prior to the Fraser Canyon field work. Further study to determine what prior knowledge and lenses for understanding help facilitate Indigenous inclusion and decolonization in PBE would be useful. In our focus group, we asked how this experience would affect their practice as teachers. One participant, for example, shared: 
I don't have to be an expert in every field we are experiencing but as teacher, I should be an experience creator. You can only do so much in the classroom. I want to be an experience cultivator and connect students to people who are holders of the knowledge. (FG-3)

This is a lovely intention, but our study did not follow the pre-service teachers into their practice and see if there was a lasting impact. Many of the studies referenced here (Aitkens \& Radford, 2018; Lowenstein et al., 2018; Marom \& Rattray, 2019; Michell et al., 2008) described the design and the reaction to the place-based experience for educators, as ours did, but no data was ever collected to study if there actually was an impact. A longitudinal study could potentially inform teacher-educators how and to what extent students took up PBE in their future work as teachers.

Although including Indigenous people into the work of PBE in a meaningful way is vital, we believe there is a role for settler educators in the work of decolonization (Greenwood, 2019; Johnson, 2010; Lowenstein et al., 2018; Madden, 2015). There needs to be more work done, however, on how to work in partnership and balance the tension between misappropriation and inclusion. Martin and colleagues (2017) also cautioned "if left with little more than some decontextualized knowledge and 'tips' for best practice, mainstream academics may remain scared to make mistakes or cause offense when teaching about Indigenous culture" (p. 1162).

Another important aspect of the work ahead is considering what deep shifts need to happen for educators engaging in decolonizing work using PBE. Greenwood (2019) recommends that educators "need to develop practices that continually support our own ontological becoming-in relationship with ourselves, each other, the land, and the cosmos itself" (p. 369). We must open our heads and our hearts and reimagine ourselves and our role as educators.

\section{References}

Aitken, A. \& Radford, L. (2018). Learning to teach for reconciliation in Canada: Potential, resistance and stumbling forward. Teaching and Teacher Education, 75, 40-48. https://doi.org/10.1016/j.tate.2018.05.014

Bang, M., Warren, B., Rosebery, A.H., \& Medan, D. (2012). Desettling expectations in science education. Human Development, 55(5-6), 302-318. https://doi.org/10.1159/000345322

Basso, K. H. (1996). Wisdom sits in places: Landscape and language among the Western Apache. University of New Mexico Press.

Battiste, M. (2013). Decolonizing education: Nourishing the learning spirit, UBC Press.

Battiste, M. \& Henderson, J. (2009). Naturalizing indigenous knowledge in eurocentric education. Canadian Journal of Native Education, 32(1), 129-130.

https://acurriculumjourney.files.wordpress.com/2014/04/battiste-henderson-2009naturalizing-indigenous-knowledge-in-eurocentric-education.pdf 
Bereiter, C. (2014). Principled practical knowledge: Not a bridge but a ladder. Journal of the Learning Sciences, 23(1), 4-17. http://doi.org/10.1080/10508406.2013.812533

British Columbia Ministry of Education, (2015) Aboriginal worldviews and perspectives in the classroom: Moving forward. https://www2.gov.bc.ca/assets/gov/education/administration/kindergarten-to-grade12/indigenous-education/awp moving forward.pdf

British Columbia Ministry of Education (2020). Building student success: BC's new curriculum. https://curriculum.gov.bc.ca/

British Columbia Teachers Council (2019). Professional standards for BC educators. https://www2.gov.bc.ca/assets/gov/education/kindergarten-to-grade-12/teach/teacherregulation/standards-for-educators/edu_standards.pdf

Cajete, G. (2000). Native science: Natural laws of interdependence. Clear Light Publishers. Cajete, G. (2014). Foreword. In L. Lee (Ed.), Diné perspectives: Revitalizing and reclaiming Navajo thought (ix-xii). University of Arizona Press.

Carey, M \& Prince, M. (2015). Designing an Australian Indigenous studies curriculum for the twenty-first century: Nakata's 'cultural interface,' standpoints and working beyond binaries. Higher Education Research \& Development, 34(2), 270-283. https://doi.org/10.1080/07294360.2014.956691

Creswell, J. W. (2013). Qualitative inquiry \& research design: Choosing among five approaches (3rd ed.). SAGE.

Dorst, K. (2011). The core of “design thinking” and its application. Design Studies, 32(6), 521532. https://www-sciencedirectcom.ezproxy.lib.ucalgary.ca/science/article/pii/S0142694X11000603

Greenwood, D. (2019). Place, land, and the decolonization of the settler soul. The Journal of Environmental Education, 50(4-6), 358-377. https://doi.org/\%EF\%BB\%BF10.1080/00958964.2019.1687412

Gruenewald, D. A. (2003). Foundations of place: A multidisciplinary framework for placeconscious education. American Educational Research Journal, 40(3), 619-654. https://www.jstor.org/stable/3699447

Gruenewald, D. A. (2008). The best of both worlds: A critical pedagogy of place. Environmental Education Research, 14(3), 308-324. https://doi.org/10.1080/13504620802193572

Hare, J. (2012). They tell a story and there's meaning behind that story: Indigenous knowledge and young Indigenous children's literacy learning. Journal of Early Childhood Literacy, 12(4), 389-414. https://doi.org/10.1177/1468798411417378

Johnson, J. T. (2012). Place-based learning and knowing: Critical pedagogies grounded in Indigeneity. GeoJournal, 77(6), 829-836. https://doi.org/10.1007/s10708-010-9379-1

Johnson, J. T. \& Murton, B. (2007). Re/placing native science: Indigenous voices in contemporary constructions of nature. Geographical Research, 45(2), 121-129. https://eportfolios.macaulay.cuny.edu/adams2013/files/2013/11/Johnson_20071.pdf 
Kennedy, M (2009). Fraser River placer miner landscapes. BC Studies, 160: The Middle Fraser, 35-66. https://doi.org/10.14288/bcs.v0i160.568

Lowenstein, E., Grewal, I. K., Erkaeva, N, Nielsen, R., \& Voelker, L. (2018). Place-based teacher education: A model whose time has come. Issues in Teacher Education, 27(2), 3652. https://www.thefreelibrary.com/PlaceBased $\% 20$ Teacher $\% 20$ Education $\% 20 \mathrm{~A} \% 20 \mathrm{Model} \% 20$ Whose $\% 20$ Time $\% 20 \mathrm{Has} \% 20 \mathrm{Come}$ .-a0549158610

Madden, B. (2015). Pedagogical pathways for Indigenous education with/in teacher education. Teaching and Teacher Education, 51, 1-15. https://doi.org/10.1016/j.tate.2015.05.005

Madden, B. (2019). A de/colonizing theory of truth and reconciliation education. Curriculum Inquiry, 49(3), 284-312. https://doi.org/10.1080/03626784.2019.1624478

Marom, L. \& Rattray, C. (2019). On the land gathering: education for reconciliation. Critical Studies in Education, 1-17. https://doi.org/10.1080/17508487.2019.1611613

Marshall, D. (2018). Claiming the land: British Columbia and the making of a new El Dorado. Ronsdale Press.

Martin, G., Nakata, V., Nakata, M. \& Day, A. (2017). Promoting the persistence of Indigenous students through teaching at the cultural interface. Studies in Higher Education, 42(7), 1158-1173. https://doi.org/10.1080/03075079.2015.1083001

McInerney, P., Smyth, J., \& Down. B. (2011). Coming to a place near you? The politics and possibilities of a critical pedagogy of place-based education. Asia-Pacific Journal of Teacher Education, 39(1), 3-16. https://doi.org/10.1080/1359866X.2010.540894

Michell, H., Vizina, Y., Augustus, C., \& Sawyer, J. (2008). Learning Indigenous science from place: Research study examining Indigenous-based science perspectives in Saskatchewan First Nations and Métis community contexts. Aboriginal Education Research Centre: University of Saskatchewan https://aerc.usask.ca/downloads/Learning-Indigenous-ScienceFrom-Place.pdf

Nakata, M. (2007). The cultural interface. The Australian Journal of Indigenous Education, 36(1), 7-14. https://doi.org/10.1017/S1326011100004646

Seixas, P., \& Morton, T. (2013), The big six historical thinking concepts. Nelson Education Ltd.

Smith, G. (2016, November 3). The past, present and future of place-based learning getting smart. https://www.gettingsmart.com/2016/11/past-present-and-future-of-place-basedlearning/

Truth and Reconciliation Commission of Canada. (2015). Truth and reconciliation commission of Canada: Calls to action. Government of Canada. http://trc.ca/assets/pdf/Calls_to_Action_English2.pdf 